Revista Temas Socio Jurídicos

Vol. 38 No 77 Julio - Diciembre de 2019

ISSN: 0120-8578

ISSN electrónico: 2590-8901

\title{
LA TRANSFUSIÓN DE SANGRE A LOS TESTIGOS DE JEHOVÁ: ¿JERARQUÍA ENTRE PRINCIPIOS CONSTITUCIONALES?
}

\author{
Jesús José Fuentes Orozco ${ }^{1 *}$ \\ Recibido: Junio 24 de 2019 \\ Aprobado: Noviembre 24 de 2019
}

\section{RESUMEN:}

La jurisprudencia constitucional colombiana ha abordado en sede de tutela casos en los que dirime la colisión del derecho a la libertad de culto de los Testigos de Jehová, con el deber del Estado de proteger la vida de sus asociados cuando aquellos se rehúsan a recibir transfusiones de sangre. En este tipo de casos, el Tribunal Constitucional colombiano no acoge jerarquía alguna entre los principios, sino que por el contrario, adopta una solución coherente con la naturaleza de mandatos de optimización que le asiste a los principios en conflicto al fomentar la búsqueda de alternativas médicas que equilibren su aplicación.

Palabras clave: Testigos de Jehová; transfusiones de sangre; principios; derecho a la salud; libertad religiosa; ponderación.

Citar este trabajo como: Fuentes Orozco, J. (2019). La transfusión de sangre a los testigos de jehová: ¿jerarquía entre principios constitucionales? En: Temas Socio-Jurídicos, 38(77), pp. 45-64. DOI: https://doi.org/10.29375/01208578.3653

1 * Magíster en Derecho, Estudiante Cursos para Doctorado en Derecho Constitucional. Orcid: https://orcid.org/0000-0003-4603-4620. Correo electronico: Jjfuentesor97@gmail. com 


\title{
BLOOD TRANSFUSION ON JEHOVAH'S WITNES- SES: HIERARCHY AMONG CONSTITUTIONAL PRINCIPLES?
}

\begin{abstract}
:
In reference to protection, the Colombian constitutional jurisprudence has addressed cases in which it resolves the conflict between Jehovah's Witnesses' rights to freedom of religion and the Government's duty to protect the life of its associates when they refuse to get blood transfusions. In such cases, the Colombian Constitutional court does not establish any hierarchy concerning the principles; on the contrary, it adopts a solution consistent with the nature of mandates of optimization which assists the court with these principles of conflict when encouraging the search of medical alternatives that balance its implementation.
\end{abstract}

Keywords: Jehovah's Witnesses; blood transfusions; principles; right to health; freedom to religion; weighting.

\section{TRANSFUSÃO DE SANGUE EM TESTEMUNHAS DE JEOVÁ: HIERARQUIA ENTRE PRINCÍPIOS CONSTITUCIONAIS?}

\section{RESUMO:}

A jurisprudência constitucional colombiana abordou em sede de tutela, casos em que resolve a colisão do direito à liberdade de culto das Testemunhas de Jeová com o dever do Estado de proteger a vida de seus associados, quando aqueles se recusam a receber transfusões de sangue. Neste tipo de casos, o Tribunal Constitucional da Colômbia não aceita nenhuma hierarquia entre os princípios, pelo contrário, adota uma solução coerente com a natureza dos mandamentos de otimização que auxiliam os princípios conflitantes, incentivando a busca de alternativas médicas que equilibrem sua aplicação.

Palavras-chave: Testemunhas de Jeová; Transfusão de sangue; Princípios; Direito à saúde; Liberdade religiosa; Ponderação.

\section{INTRODUCCIÓN}

La Constitución colombiana de 1991 presenta un amplio catálogo de derechos reconocidos a favor de sus asociados, dentro de los cuales se encuentran la vida, la libertad de culto y la salud, derechos que ocupamos en este estudio. Es claro que estos derechos no imponen únicamente un 
comportamiento pasivo al Estado, al impedirle invadir la esfera propia de los mismos en desmedro de la persona, sino que, dependiendo de la tipología del derecho correspondiente, también le adjudican deberes positivos a partir de los que esa estructura político-jurídica deberá adoptar un papel activo para realizar esas garantías esenciales.

Enfocándonos en esos deberes positivos encontramos que la Carta Política obliga al Estado a velar por la vida y la salud de sus asociados, adoptando todas las medidas necesarias, tanto idóneas como proporcionales, las cuales permiten la realización de ese derecho, elemento integrador del deber estatal de garantizar la vida de sus asociados (Corte Constitucional, sentencia T-171 de 2018).

A pesar de la consagración de estos derechos y deberes como referentes para asegurar la vida tanto a nivel individual como comunitario, nada obsta para que en situaciones concretas se presenten colisiones entre los mismos, tal y como ocurre en las transfusiones de sangre a miembros de la comunidad religiosa de los Testigos de Jehová. Los integrantes de esta religión rechazan la posibilidad de recibir transfusiones de glóbulos rojos y blancos, plaquetas y plasma, en virtud de lo señalado en diversos preceptos bíblicos como el Levítico 17:14, que de acuerdo con Besio y Besio (2006) se advierte que “(...) toda la vida es sangre, quien la comiere será exterminado" (p. 275).

Desatender la voluntad de Dios implica, en la perspectiva de esta religión, renunciar a la promesa de resurrección, sin perjuicio del desligamiento social que ello representa. Vale aclarar que esta renuncia implícita a la comunidad religiosa no aplica cuando la transfusión se recibe en contra de la voluntad del Testigo, o si media el arrepentimiento de este durante el proceso interno que le adelanta la comunidad por haber pretermitido el mandato en comento (Besio y Besio, 2006, p. 276).

En tales eventos, es clara la tensión entre la libertad de cultos que ampara al Testigo de Jehová quien legitima su decisión de rehusarse a recibir transfusiones de sangre y el deber del Estado de asegurar la vida y salud de sus asociados, situación que ha merecido la atención de la jurisprudencia de la Corte Constitucional colombiana; esta Corporación ha advertido que en el marco de la tensión referida es necesario respetar la manifestación de voluntad de la persona, sin que sea posible que las autoridades la desconozcan e invadan el fuero interno del sujeto; justamente esta tensión será el tema sobre el que recaerá el estudio a efectuar en las siguientes líneas.

A partir del tema advertido y de la jurisprudencia de la Corte Constitucional colombiana sobre el mismo, nos preguntamos si es posible afirmar que en los casos de transfusiones sanguíneas a Testigos de Jehová se evidencia una jerarquización de principios constitucionales, en donde la libertad religiosa prevalece sobre el derecho a la salud y el deber del 
Estado de asegurar la vida de sus asociados. Esto por cuanto, prima facie, así pareciera desprenderse de la doctrina de ese Tribunal, según la cual no es posible desconocer los efectos de las exteriorizaciones religiosas del Testigo de Jehová sometido a tratamiento médico.

Frente a la pregunta señalada ut supra, plantearemos como hipótesis que en la jurisprudencia constitucional colombiana sobre transfusiones de sangre a Testigos de Jehová no se evidencia una jerarquización de principios sino la aplicación de la condición de mandato de optimización que caracteriza a estos últimos. De allí que se pretenda aprovechar el máximo posible de la libertad religiosa junto con el máximo posible del derecho a la salud, para adoptar la solución al caso concreto.

La metodología a emplear en este texto será de carácter analítico; se toma como insumo principal la jurisprudencia de la Corte Constitucional colombiana de 1991, y parte de la doctrina relacionada con el mandato de optimización, sin perjuicio de algunas referencias doctrinarias foráneas sobre el particular.

La presente contribución tendrá como ruta expositiva un primer apartado relacionado con (1) la jurisprudencia constitucional colombiana sobre las transfusiones sanguíneas a los Testigos de Jehová, a través del estudio (1.1) de la esencia y connotaciones del derecho a la salud, (1.2) algunos aspectos básicos de la libertad religiosa, y (1.3) la jurisprudencia constitucional colombiana sobre las transfusiones de sangre a los Testigos de Jehová; luego, se analizará (2) el mandato de optimización como criterio definitorio de la tensión entre la libertad religiosa y el derecho a la salud, haciendo énfasis en (2.1) la legitimidad de la conducta estatal desde los derechos fundamentales, y (2.2) la noción de mandato de optimización. Por último, a la luz del (3) mandato de optimización se analizarán los casos concretos y, desde allí, validar la hipótesis correspondiente.

\section{La jurisprudencia constitucional colombiana y la tensión entre la libertad religiosa y la salud en las transfusiones sanguíneas a los Testigos de Jehová}

En el marco de una sociedad pluralista en la que se reconocen derechos y deberes desde la constitución política, es posible que el ejercicio de la libertad religiosa conlleve colisiones con algunos deberes estatales, como por ejemplo la protección a la salud y a la vida del asociado. Allí se denota una tensión entre principios constitucionales, presente en otros ordenamientos jurídicos.

\subsection{Esencia y connotaciones del derecho a la salud}

Tomando como pauta conceptual primigenia la jurisprudencia de la Corte Constitucional colombiana en relación con el derecho a la salud, inicialmente interesa precisar qué se ha entendido en esta instancia por salud. 
Para ese Tribunal, la salud apunta a un estado variable de la persona que puede ser afectado por múltiples situaciones que incidirán necesariamente en su condición física, mental y/o social. Esto lleva a que la salud sea una cuestión de grado que habrá de valorarse en cada caso puntual (Corte Constitucional, Sala Segunda de Revisión, sentencia T-760 del 2008).

Al abordarlo desde la connotación de derecho, la misma Corporación ha resaltado que se trata de una garantía compleja no solo por su contenido sino por las múltiples obligaciones derivadas de aquel. La consecuencia inmediata de esa complejidad es que la garantía plena del derecho a la salud se encuentra necesariamente relacionada con la disponibilidad de recursos a nivel institucional y presupuestal ${ }^{2}$.

La Corte Constitucional tiende a conceptualizar el derecho a la salud de una manera amplia, al considerar que abarca los procedimientos necesarios para asegurar la estabilidad tanto física como mental de la persona a través de medidas preventivas y reactivas. Sobre el particular, el Tribunal, cuya doctrina se comenta, dispuso que la salud apunta a:

(...) la normalidad orgánica funcional, tanto física como en el plano de la operatividad mental, y de restablecerse cuando se presente una perturbación en la estabilidad orgánica y funcional de su ser. Implica, por tanto, una acción de conservación y otra de restablecimiento. (Corte Constitucional, Sala Plena, sentencia C-776 del 29 de septiembre de 2010)

La doctrina ha aportado elementos relevantes para entender la naturaleza y alcance del derecho a la salud. Este derecho puede enmarcarse en la categoría de derechos sociales fundamentales, que según Arango (2012), está integrada por aquellos que tienen una importancia elevada y que entrañan un fuerte componente de hacer que debe asumir el Estado. Así lo dispone Arango cuando señala que son:

(...) derechos subjetivos con un alto grado de importancia. Pero lo que distingue a los derechos sociales fundamentales de otros derechos fundamentales es que son "derechos de prestación en su sentido estrecho", es decir, derechos generales positivos a acciones fácticas del Estado. (2012, pp.37-38)

2 Este comentario se hace teniendo en cuenta que en Colombia un alto volumen de tutelas relacionadas con el derecho a la salud obedece a la necesidad de prestar servicios que no se encuentran en el llamado Plan Obligatorio de Salud. Sin embargo, la jurisprudencia constitucional ha advertido que esta no es una circunstancia que comprenda una razón suficiente para sacrificar el derecho a la salud de la persona y, en consecuencia, por vía de solicitudes de amparo se podía lograr que se ordene la prestación del servicio. Esta situación fue abordada por la Corte Constitucional en la citada Sentencia T-760 de 2008, Magistrado Ponente Dr. Manuel José Cepeda Espinosa. 
Esta categoría de derechos, que resalta su relevancia a pesar de incluir el componente prestacional, constituye una herramienta valiosa para hacer frente a la pobreza, a la desigualdad y a la lucha contra las necesidades insatisfechas, tendencia introducida desde la constitución de Querétaro de 1917 (Bernal, 2018, p. 173).

Teniendo claros estos objetivos, así como la mayor relevancia y la carga prestacional que conlleva para el Estado, en Colombia existe un sistema de salud definido por el artículo $4^{\circ}$ de la Ley 1751 de 2015, "Por medio de la cual se regula el derecho fundamental a la salud y se dictan otras disposiciones" (Ley 1751, 2015), de la siguiente manera:

(...) el conjunto articulado y armónico de principios y normas; políticas públicas; instituciones; competencias y procedimientos; facultades, obligaciones, derechos y deberes; financiamiento; controles; información y evaluación, que el Estado disponga para la garantía y materialización del derecho fundamental de la salud.

Partiendo de la integración allí descrita, tenemos que existen diversos actores encargados de salvaguardar el derecho social fundamental a la salud, pues no solo el Estado y las Entidades Promotoras de Salud (EPS), en su calidad de instituciones, tienen el deber de asegurar su efectividad. El modelo planteado por la Ley 100 de 1993, "Por la cual se crea el sistema de seguridad social integral y se dictan otras disposiciones" (Ley 100, 1993) en materia de salud se rige por el llamado pluralismo estructurado, que apunta a la necesaria interacción entre las instituciones y la sociedad para alcanzar los objetivos en que se fundamenta la prestación del servicio de salud (Arenas, 2018, pág. 507).

Para alcanzar este objetivo, existe un Plan Obligatorio de Salud (POS) ofrecido por esas entidades promotoras, el cual está enfocado en brindar acceso a los medicamentos y tratamientos necesarios para garantizar su faceta de atención correctiva. Empero, ello no obsta para que otros agentes como la familia y la sociedad participen brindando el apoyo y protección necesarios para salvaguardar este derecho (Corte Constitucional, Sala Plena, Sentencia C-776 del 29 de septiembre de 2010), en una fase de naturaleza preventiva.

Hecha la claridad de que la salud conlleva una serie de obligaciones preventivas y correctivas en las que intervienen tanto los actores del sistema de seguridad social como la familia y la sociedad, cuya finalidad no es otra que asegurar la integridad psicofísica de la persona, cabe anotar que la gama de prestaciones a las que se puede acceder en el marco del derecho a la salud no se limitan al Plan Obligatorio de Salud, pues como ha señalado la Corte Constitucional: 
(...) En tal sentido, el ámbito del derecho fundamental a la salud está delimitado por la dogmática constitucional, que reconoce los contenidos garantizados a las personas en virtud del mismo. El ámbito de protección, por tanto, no está delimitado por el plan obligatorio de salud. Puede existir un servicio de salud no incluido en el plan, que se requiera con necesidad y comprometa en forma grave la vida dignidad de la persona o su integridad personal. (Corte Constitucional, Sala Segunda de Revisión, Sentencia T-760 del 2008)

Esta apreciación del Tribunal Constitucional no resulta menor, pues implica aceptar la posibilidad que el juez de tutela intervenga en la política pública de salud para garantizar la materialización de este derecho social fundamental. Esto, en la medida en que los jueces son actores unitarios de las políticas públicas, encargados de intervenir para garantizar la supremacía de la Carta ante eventos de vulneración reiterada y masiva de los derechos allí reconocidos (Delgado, 2018, pp. 104-105).

La forma en la que se encuentra concebido el derecho a la salud, de acuerdo con la normatividad y jurisprudencia colombiana, permite afirmar que él mismo es una consecuencia del constitucionalismo social, lo que hace, tanto viable como necesario, reconocer una serie de derechos enfocados en asegurar la equidad en las relaciones jurídicas y económicas, cuya carga prestacional corresponderá al Estado para realizar los fines de su esencia (Valadés, 2013, p. 33). Este derecho, en el mismo marco del constitucionalismo social, alude a un bien que el hombre necesita para disfrutar de su dignidad y ejercer efectivamente sus espacios de libertad (Bidart, 1988, p. 140).

\subsection{La libertad religiosa como derecho fundamental}

El artículo $1^{\circ}$ de nuestra Constitución Política ${ }^{3}$ dispone que el pluralismo es una de las características del Estado Social de Derecho adoptado por Colombia. De acuerdo con Haberle (2007), ese pluralismo, como componente esencial de un Estado constitucional, se traduce en la diversidad de intereses e ideas concurrentes en una misma sociedad, así como en el deber para el Estado de asumir el cumplimiento de las tareas que aseguren la efectividad de ese pluralismo (pp. 322-323).

Según Haberle (2007), el pluralismo al que venimos haciendo mención parte de la existencia de una sociedad abierta en la que la tolerancia se erige como un principio constitucional (p. 323). La coexistencia de ideas e intereses a la que hicimos referencia en el acápite anterior debe enfocarse en la consecución del bien común, de la siguiente manera:

3 El artículo citado dispone que "Colombia es un Estado social de derecho, organizado en forma de República unitaria, descentralizada, con autonomía de sus entidades territoriales, democrática, participativa y pluralista, fundada en el respeto de la dignidad humana, en el trabajo y la solidaridad de las personas que la integran y en la prevalencia del interés general”. (Const., 1991) 
El Estado constitucional desarrolla sus propias fuerzas a partir del paralelogramo de las fuerzas que resulta de numerosas ideas e intereses. La consecuencia es una "teoría pluralista del bien común", así como el reconocimiento de los grupos de interés y las asociaciones, religiones, iglesias y partidos pluralistas. (p.323)

La perspectiva de Haberle (2007) sobre el pluralismo como elemento esencial del Estado constitucional implica reconocer que existe un principio de tolerancia según el cual, en una sociedad abierta deben reconocerse y protegerse la coexistencia de diversos intereses e ideas que representan los diversos grupos presentes, actuando desde allí para alcanzar el bien común.

Como uno de los diversos elementos desde los cuales se desarrolla el pluralismo, encontramos la libertad personal. Esta no debe entenderse como un único derecho, pues como bien lo advierte Araújo (2015), la libertad personal conlleva una serie de garantías cuyo propósito es impedir que la esfera individual sea en algunos ámbitos objeto de interferencias tanto de los poderes públicos como privados (p. 542). Dentro de ellas, y como un desarrollo del pluralismo, aparece la libertad religiosa.

El derecho fundamental a la libertad religiosa, consagrado en el artículo 19 de nuestra Constitución ${ }^{4}$, parte de un supuesto elemental: la protección de la coherencia entre el fuero interno de la persona y su exteriorización. Esto es así en la medida que todas las personas tienen una esfera íntima que se erige como espacio propicio para acoger un credo u orientación religiosa y asumir los postulados que mejor se acompasen con su visión del mundo. Sin embargo, esta esfera se vería anulada si se impidiera la exteriorización de esas convicciones; tal situación terminaría anulando la libertad interior del individuo. Este derecho permite:

(...) reunir en un todo los actos internos y externos que conllevan a la expresión de la religiosidad de una persona, mediante los cuales los creyentes logran alcanzar un estado de coherencia entre su vida personal y los dogmas de su religión. (Corte Constitucional, sentencia T-823 de 2002)

En otros términos, para el Tribunal Constitucional la libertad religiosa le permite a toda persona, en ejercicio de su autonomía, acoger o no una determinada religión, derecho que a su turno conlleva la garantía a mantener la integridad de la creencia personal (Corte Constitucional, sentencia T-823 de 2002). Esta última garantía resulta indispensable para la efectividad real de la libertad religiosa, pues aceptar que la asunción y expresión de un credo puedan ser limitados o anulados, implicaría desdibujar el alcance real de este derecho, que no es otro que asegurar la coherencia entre el fuero interno religioso y su expresión externa.

4 El artículo 19 de nuestra Ley Mayor dispone que "Se garantiza la libertad de cultos. Toda persona tiene derecho a profesar libremente su religión y a difundirla en forma individual o colectiva.

"Todas las confesiones religiosas e iglesias son igualmente libres ante la ley". (Const., 1991) 
De igual manera, resulta oportuno señalar que la libertad religiosa tiene diversos componentes que definen su sentido y alcance dentro de una sociedad pluralista. Así, la libertad de conciencia, de culto, el derecho de los padres a orientar en el ámbito religioso a sus hijos hasta que alcancen la mayoría de edad, así como el derecho a no sufrir discriminación como consecuencia de su religión y el derecho a no participar en actos que atenten contra sus convicciones, hacen parte de la libertad reseñada (Bidart, 2016, pp. 80-81).

Por último, la libertad religiosa también conlleva una faceta activa para el Estado, congruente con la dimensión prestacional de las libertades. El Estado no solo tiene la obligación de evitar medidas que puedan menoscabar el ejercicio de este derecho, sino de adoptar normas y acciones que aseguren el respeto del mismo (Corte Constitucional, sentencia SU-626 de 2015).

\subsection{Casos concretos de transfusiones de sangre a Testigos de Jehová en la jurisprudencia del Tribunal Constitucional colombiano}

Presentada grosso modo la concepción de la salud en la jurisprudencia de la Corte Constitucional colombiana, así como algunos elementos relevantes para comprender la esencia de la libertad religiosa, a continuación nos enfocaremos en algunos eventos en los que se ha debido solucionar la tensión entre la libertad religiosa ${ }^{5}$, de la que se desprende la protección del credo de los Testigos de Jehová, con el derecho a la salud y el deber estatal y médico de velar por la vida de los pacientes ${ }^{6}$, ya que, se itera, dicha congregación religiosa no admite las transfusiones de sangre por considerarlas un acto que impide alcanzar la vida eterna.

Un primer caso que merece análisis lo encontramos en la sentencia T-474 del 25 de noviembre de 1996, en el que un menor de edad Testigo de Jehová rechazó una transfusión de sangre siguiendo los lineamientos propios de su fe. Sin embargo, su padre se opuso a esta negativa, por lo que fue necesario acudir a la acción de tutela para dirimir el conflicto planteado. El caso fue resuelto, se ordenó que se tuviera en cuenta la posición del padre de familia para tomar la decisión médica sobre el tratamiento, conclusión a la que la Corte arribó luego de advertir que, tratándose de un menor adulto, su capacidad -limitada por la ley- debe ser complementada con el consentimiento del padre para así poder afirmar que la decisión fue adoptada con base en la capacidad plena del paciente.

5 Estas disposiciones constitucionales guardan consonancia con los artículos 18 de la Declaración Universal de Derechos Humanos y del Pacto Internacional de Derechos Civiles y Políticos, tal como lo advierte la Corte Constitucional colombiana en la jurisprudencia que se comenta.

6 Derivada de los artículos 2 y 48 de la Constitución Nacional, principalmente. 
En casos como el expuesto, los padres no solo pueden ejercer su derecho a guiar a sus hijos, sino que también están facultados para intervenir en la toma de la decisión sobre la transfusión de sangre al menor Testigo de Jehová. La capacidad es compartida entre los padres y el hijo.

Si se presenta contradicción entre las decisiones que tome el menor, que ponen en peligro su derecho fundamental a la vida, y las decisiones de sus padres para preservarla, le corresponde al Estado garantizar la primacía del derecho fundamental a la vida del menor por conducto de la intervención de los padres. (Corte Constitucional, Sentencia T-474 del 25 de noviembre de 1996)

En la jurisprudencia analizada, la Corte también tuvo en cuenta la noción de caso extremo, es decir, aquel en el que se requieren intervenciones o tratamientos urgentes e inmediatos para poder preservar la vida del paciente. Este fue un aspecto adicional para que la Corte, tratándose de un menor Testigo de Jehová, admitiera darle prelación a la posición del padre y autorizara al personal médico para adelantar las acciones necesarias para salvar la vida del paciente, aún en contravía de sus creencias. Allí, el padre está haciendo uso de sus derechos para asegurar un objetivo constitucionalmente relevante como la salvaguarda de la vida del menor (Corte Constitucional, sentencia T-474 del 25 de noviembre de 1996).

De otro lado, la Sentencia T-659 del 15 de agosto de 2002 merece un breve comentario ${ }^{7}$. Allí nuevamente se abordó el caso de una paciente Testigo de Jehová que rechazó la transfusión sanguínea como parte de un tratamiento que debía seguirse para recuperar su salud. En esta providencia, la Corte afirmó que ni siquiera las decisiones del juez de los derechos fundamentales serían un instrumento legítimo para desconocer manifestaciones autónomas ligadas a la libertad religiosa, máxime si esa exteriorización del credo se hace de manera consciente por parte del titular del derecho (Corte Constitucional, sentencia T-659 del 15 de agosto de 2002). Si el paciente manifestó de forma clara y expresa, en uso pleno sus facultades mentales su voluntad de no aceptar la transfusión, ni siquiera el juez constitucional está habilitado para tomar una decisión en sentido contrario, pues ello equivaldría a anular la libertad religiosa del paciente.

En la sentencia T-471 de 2005 la Corte asumió como referente inicial de análisis que el Estado Social de Derecho, como modelo de organización sociopolítica acogido por el Estado colombiano, concibe al hombre como un sujeto dotado de libertad y autonomía, como un fin en sí mismo. A partir de estos ejes debe gravitar la actuación de las estructuras políticas y jurídicas que lo componen. La razón se presenta como un atributo que

7 Los casos que se analizan en adelante tienen hechos similares: pacientes miembros de la comunidad de los Testigos de Jehová que se rehúsan a recibir tratamientos que impliquen transfusiones de sangre. 
define al individuo y que constituye un presupuesto esencial de las ya mencionadas autonomía y libertad del sujeto (Corte Constitucional, Sala Novena de Revisión, Sentencia T-471 del 10 de mayo de 2005).

Con base en lo anterior, las decisiones emanadas de un individuo que goce de la plenitud de sus capacidades estarán amparadas por la autonomía y libertad que la misma Constitución le reconocen. En los casos en que previo conocimiento de las opciones, implicaciones y consecuencias del tratamiento requerido para proteger su salud, el sujeto dé prevalencia a sus convicciones religiosas, esta determinación se verá cobijada y legitimada por el ordenamiento jurídico. No será admisible que el galeno tratante busque hacer prevalecer su criterio basado en la condición científica del mismo, pues significaría cercenar elementos definitorios de la subjetividad que pretende afianzar el Estado Social de Derecho (Corte Constitucional, Sala Novena de Revisión, Sentencia T-471 del 10 de mayo de 2005).

Más adelante, la Corte recordó en la Sentencia T-052 del 2010 que es indispensable contar con el consentimiento informado del paciente, lo que se traduce en una manifestación de voluntad libre y razonada sobre la aceptación o no de un procedimiento o medicamento puntual. En esa decisión judicial llama la atención que esa Corporación advirtió que tal manifestación de autonomía debe adelantarse "verificando en todo caso, que no incumpla con la obligación que tiene de preservar en todo momento su vida, integridad personal y su salud y además que, con ello no cause daño a los demás" (Corte Constitucional, Sala Segunda de Revisión, Sentencia T-052 del 2 de febrero de 2010). Este apartado de la jurisprudencia constitucional, en consonancia con lo señalado en el acápite precedente, resulta bastante curioso, pues es natural que eventualmente una manifestación en el sentido de no asumir un determinado tratamiento pueda tener repercusiones negativas en la salud del paciente.

La Corte optó por revocar la decisión que dispuso denegar el amparo solicitado y, en consecuencia, ordenó a la EPS que presentara otras opciones médicas al paciente para adelantar el tratamiento que lo ayudara a recobrar su integridad física, sin que involucrara transfusiones de sangre. Empero, esta decisión no fue unánime, pues uno de los jueces de la Corte Constitucional emitió un voto particular al considerar que en este caso no se presentó vulneración alguna de derechos fundamentales (Corte Constitucional, Sala Segunda de Revisión, sentencia T-052 del 2 de febrero de 2010).

El juez disidente advirtió que la libertad religiosa solo permite que el paciente escoja libremente si desea asumir o no la aplicación de un medicamento o procedimiento específico en su caso, pero no por ello puede imponerse la obligación a la EPS de ofrecer diversas alternativas, pues 
este no es un aspecto que se encuentre atado indefectiblemente a la polimencionada libertad religiosa (Corte Constitucional, Sala Segunda de Revisión, sentencia T-052 del 2 de febrero de 2010).

Por último, en la Sentencia T-476 del 2016 la Corte reconoció la tendencia natural del ser humano a exteriorizar un credo, lo que le lleva a ligar su vida a unos dictados emanados de la deidad o ser superior propio de cada religión. De esta manera, el estilo de vida del hombre se verá permeado por los mandatos aludidos, y es por ello que la Ley Mayor colombiana reconoce la libertad religiosa, facultando a toda persona para que acoja o no en su vida personal esos postulados religiosos. Este derecho, afirma la Corte, entraña manifestaciones de la autonomía individual, pero de ninguna manera podrá considerarse como un absoluto, pues el mismo ordenamiento jurídico, los derechos que le asisten a los coasociados, el eventual abuso de los derechos propios y la necesaria prevalencia del interés general constituyen talanqueras a su ejercicio desmedido. (Corte Constitucional, Sala Segunda de Revisión, Sentencia T-476 del $1^{\circ}$ de febrero de 2016).

Armonizadas estas consideraciones con el caso de los Testigos de Jehová que rechazan los tratamientos médicos que involucran transfusiones sanguíneas, es menester señalar que la Corte recuerda que el médico tratante debe presentarle al paciente la información suficiente relacionada con los tratamientos disponibles para cada patología, en aras de que el paciente adopte una decisión libre y espontánea sobre la forma en que desea que se aborde la dolencia o enfermedad. Esto le permitirá decidir si rechaza o no los procedimientos que no se avengan a sus creencias (Corte Constitucional, Sala Segunda de Revisión, Sentencia T-476 del $1^{\circ}$ de febrero de 2016).

Finalmente, vale anotar que esta tensión no ha sido privativa de la jurisprudencia constitucional colombiana. Como advierte Pregno (2013), en Argentina se presentó el llamado Caso Albarracini, en el que un paciente Testigo de Jehová había manifestado y protocolizado el rechazo de transfusiones sanguíneas en caso de que eventualmente las necesitara, decisión corroborada por su cónyuge. Sin embargo, su padre se opuso a esa determinación basado, principalmente, en el estado grave de salud en que se encontraba su hijo. La Corte Suprema de Justicia de la Nación confirmó la decisión de negar lo propuesto por el padre del paciente, desestimó, incluso la opinión del Procurador General de la Nación, para quien debía prevalecer el deber estatal de salvar la vida del paciente (Pregno, 2013, pp. 125-129). En este caso se dio clara prevalencia a la autonomía religiosa del paciente.

\section{El mandato de optimización como criterio definitorio de la tensión entre la libertad religiosa y el derecho a la salud}

El Estado se legitima en la medida que fomente y haga efectivos los principios constitucionales. Sin embargo, es posible que se presenten conflictos entre estos en los que, para su resolución, deberá tenerse en cuenta 
su condición de mandatos de optimización y la metodología propia para solucionar las tensiones entre principios.

\subsection{Breve comentario: la legitimidad de las actuaciones del Estado}

A lo largo de la historia se ha acudido a diversos criterios a partir de los cuales se ha pretendido legitimar tanto la existencia del Estado como los comportamientos de sus agentes. En la actualidad, uno de los criterios de legitimidad más importantes que deben observar las autoridades públicas lo encontramos en los derechos fundamentales.

Más a fondo, legitimar la actuación estatal desde esta clase de derechos implica, además de reconocer y asegurar la efectividad de los mismos, generar las condiciones necesarias para que esto último suceda, sin importar si el deber ínsito al derecho fundamental de que se trate implique un comportamiento activo o pasivo. Sobre el particular, Ferreyra (2015) enseña que:

Sí, en cambio, al Estado se lo considera un instrumento (de la razón), el ente únicamente se legitima si tutela y satisface los derechos fundamentales. Es más: aquí el Estado no solo es el que confiere los derechos fundamentales, sino que además debe generar las condiciones para su realización, ya sea por abstención o por prestación. En este caso, a diferencia del anterior, el Estado debe legitimarse mediante la procreación y respeto del ambiente necesario para la realización de los derechos fundamentales. (p. 47)

En tal orden de ideas, el Estado tiene el deber de buscar alternativas que conduzcan a optimizar la efectividad de los principios constitucionales y de los derechos fundamentales. Una de las herramientas a través de las que se puede consumar este deber la encontramos en el concepto de mandato de optimización, así como en el empleo de la ponderación para solucionar controversias de naturaleza principialista o iusfundamental.

\subsection{La noción de mandato de optimización}

Hemos destacado la tensión que en los casos comentados se suscita entre los principios constitucionales que aseguran la libertad religiosa, y el papel del Estado como garante de la vida y de la salud de las personas que habitan en su territorio. Ante este panorama, se hace necesario considerar un elemento definitorio de los principios, como lo es el llamado mandato de optimización.

Actualmente, poco se duda de la pertenencia de los principios al ordenamiento jurídico. Este último, también compuesto por reglas, deberá afrontar, eventualmente, algunas tensiones derivadas de la posible aplicación de dos principios a un mismo caso. De acuerdo con Alexy (2012), 
uno de los puntos que permite diferenciar los principios de las reglas yace en que aquellos deben realizarse, en la mayor medida posible, siempre que se observen las posibilidades jurídicas y fácticas de cada caso particular (p. 67). A partir de esta característica precisa, se advierte que los principios son “(...) mandatos de optimización, que se caracterizan porque pueden cumplirse en diferente grado y que la medida debida de su cumplimiento no solo depende de las posibilidades jurídicas que se determinan por los principios y reglas opuestos" (Alexy, 2012, pp. 67-68).

Empero, como advertimos, las colisiones entre principios en un caso puntual son posibles. Cuando estas ocurren, uno de los principios habrá de ceder ante el otro, pero no por razones de validez, sino de peso en la situación específica. El principio mayormente afectado en ningún caso quedará invalidado, sino que, en el evento concreto, deberá ceder para salvaguardar elementos de mayor importancia ligados al principio con el que colisiona. Esto implica que mientras los conflictos entre reglas se producen en la dimensión de la validez, los que involucren principios lo harán en la dimensión del peso (Alexy, 2012, pp. 70-71).

Este mandato de optimización implica que los principios deban ser realizados de la manera más completa posible, en donde, a su vez, se atiendan las posibilidades jurídicas y fácticas. Según Alexy (2016), las posibilidades fácticas se relacionan con los principios de adecuación y necesidad, mientras que las jurídicas se enfocan en la ponderación (p. 21). En este último caso, la ponderación en sentido estricto, apunta a confirmar que cuando se sacrifique parte de uno de los principios en colisión la importancia del cumplimiento del otro debe ser aún mayor a la luz del dictado constitucional (Alexy, 2016, p. 21).

Esta conceptualización es reiterada por Bernal (2008), para quien los principios no determinan lo que debe o no hacerse, sino que conllevan a realizar algo, en la mayor medida posible, desde las esferas fáctica y jurídica. Por ello, afirma que "Las posibilidades jurídicas están determinadas por los principios y reglas opuestas, y las posibilidades reales se derivan de enunciados fácticos" (p. 97).

No hay lugar a dubitación alguna en relación con la forma en que deben abordarse las colisiones entre principios: al encontrarse en la dimensión del peso y no de la validez, debe buscarse la mayor aplicación de cada uno de los elementos en pugna. Sacrificar parte de los componentes de un principio será legítimo siempre que se demuestre la mayor relevancia de aquel cuyo peso se superpone. Esta concepción obliga a asumir una metodología para solucionar las colisiones entre principios, pues este asunto no debe quedar sujeto al libre albedrío del juez constitucional.

La metodología propia de este tipo de conflictos la encontramos en la ponderación, herramienta argumentativa que pretende establecer de 
manera racional, en cada caso específico, cuál de los principios tiene un mayor peso, y desde allí solucionar la controversia correspondiente. Los pasos en que se desarrolla pueden resumirse de la siguiente manera:

- En primera medida, se debe revisar el cumplimiento de la idoneidad de la norma o medida bajo análisis. Esta pauta es sintetizada por Clérico (2009) así: "El mandato de la adecuación técnica exige la implementación de un medio cuyos efectos contribuyan al fomento del fin perseguido" (p. 43).

- Superada satisfactoriamente la evaluación del primer elemento, debe analizarse la necesidad, estableciendo si “ ¿Se puede evitar la restricción del derecho a través de otro medio, o por lo menos, reducir el grado de limitación? (Clérico, 2009, p. 101).

- Por último, se aborda la proporcionalidad en sentido estricto; requisito en el que se debe cumplir con el equilibrio entre la restricción a uno de los principios, y la idoneidad y necesidad de la medida. La regla anterior se resume con el siguiente postulado:

Cuando (el medio dado es adecuado técnicamente y el menos lesivo y) la restricción iusfundamental guarda una relación proporcional en sentido estricto con el fin estatal legítimo (que pretende justificar la intensidad de la restricción iusfundamental), entonces la medida es proporcional en sentido amplio. (Clérico, 2009, pp. 164-165)

Agotada la metodología indicada, se puede concluir si la limitación de un principio o derecho fundamental en un caso específico resulta acorde o no con los mandatos constitucionales ${ }^{8}$.

\section{Aplicación del mandato de optimización en los casos referidos}

En las decisiones jurisprudenciales que hemos abordado, la Corte ha afirmado que ni aún el juez constitucional actuando desde la óptica de los derechos fundamentales puede desconocer la voluntad del paciente Testigo de Jehová, y que la libertad religiosa es una forma de expresión de la autonomía personal, aspecto que necesariamente irá de la mano con la dignidad inherente al ser humano. Nuevamente advertimos que estas parecieran características que llevan a considerar la libertad religiosa como un derecho absoluto sobre el que el Estado no puede intervenir, ni aun argumentando desde la necesidad de asegurar la vida y la salud del paciente. Sin embargo, esta concepción absolutista se aleja en demasía de la realidad jurídica del asunto.

8 Debemos advertir que el presente análisis no tiene como objetivo central estudiar la metodología propia del examen de proporcionalidad. Por ello, tan solo enunciamos que el mismo debe ser empleado cuando se trate de resolver colisiones entre principios constitucionales. 
En primer lugar, debemos traer a colación lo que la misma jurisprudencia constitucional ha denominado doctrina de la convivencia, a partir de la cual los derechos -en este caso ligados a principios- pueden hacerse compatibles desde su misma relatividad, siempre y cuando no se pongan en riesgo o lesionen otros derechos fundamentales, y menos aún, se afecten derechos a nivel colectivo (Corte Constitucional, Sala Quinta de Revisión, Sentencia T-823 del 4 de octubre de 2002). Partiendo de esa doctrina, es claro que debe buscarse el punto de equilibrio entre los derechos en colisión.

También quedó claro que la jurisprudencia constitucional colombiana demanda la presencia del consentimiento informado del paciente, aspecto que igualmente se presenta en el caso de la jurisprudencia argentina, mencionada anteriormente. Es indispensable que exista una manifestación informada, persistente y cualificada de la voluntad del paciente sobre la aceptación o no de la práctica de un procedimiento o tratamiento.

El consentimiento es informado cuando se suministran al paciente todos los elementos de juicio requeridos para avalar o rechazar el actuar presentado por el galeno. Al exigir que el consentimiento sea persistente, se busca que la información dada al sujeto pasivo del tratamiento se mantenga vigente mientras el mismo dure. Finalmente, al requerir que el consentimiento sea cualificado, se busca que conste clara y expresamente por escrito (Corte Constitucional, Sala Segunda de Revisión, Sentencia T-476 del $1^{\circ}$ de febrero de 2016).

La finalidad de esta exigencia no es otra que respetar la autonomía de la persona y la expresión de credo del paciente, brindando información suficiente para que este, de manera autónoma, decida lo que considere coherente con su cosmovisión y estilo de vida, al tiempo que constituye un instrumento para que el médico tratante salvaguarde responsabilidades por su actuación.

Por último, y como reflejo de la observancia de los principios como mandatos de optimización, tenemos que la Corte Constitucional ha partido del hecho que la ciencia ofrece algunas posibilidades para que los procedimientos médicos se adelanten sin acudir a transfusiones de sangre (Corte Constitucional, Sala Segunda de Revisión, Sentencia T-052 del 2 de febrero de 2010). Esta es la razón por la cual, una forma de optimizar el derecho a salud con las creencias de los Testigos de Jehová, es ofreciéndole dentro de las posibilidades que brinda actualmente la ciencia, acceder a procedimientos y tratamientos que no impliquen trasplantes sanguíneos.

Es importante detenernos en el salvamento de voto a la sentencia T-052 del 2 de febrero de 2010, donde el juez disidente manifestó que no existía vulneración alguna de los derechos del accionante, en la medida que la obligación de la entidad promotora de salud iba hasta poner a disposición del paciente el tratamiento correspondiente para recuperar su salud, mas no implicaba tener que presentarle obligatoriamente diversas 
alternativas para encontrar alguna compatible con su posición religiosa.

Si bien es cierto, la razón expuesta por el togado que emitió el voto particular es clara, no puede pasarse por alto que al analizar la necesidad de la medida adoptada por la entidad promotora de salud -ofrecer un tratamiento que implicaba transfusión de sangre-, se tiene que la misma no superaba este paso del examen de proporcionalidad, toda vez que existían alternativas de tratamiento que no implicaban efectuar transfusiones, las cuales permitirían armonizar la protección de la vida del paciente con su concepción religiosa.

Superado este punto, tenemos que la condición de mandatos de optimización que le asiste a los principios se puede apreciar en la medida en que la Corte, para absolver las solicitudes de amparo sobre transfusiones sanguíneas para Testigos de Jehová, inicialmente identifica los valores, principios o derechos en pugna, que como hemos indicado en múltiples oportunidades a lo largo del presente escrito, son la libertad religiosa y los derechos a la vida y a la salud, puntualmente desde la óptica de protección que frente a estos asume el Estado.

En síntesis, la Corte Constitucional observa el mandato de optimización cuando se enfrentan la libertad de cultos y los derechos a la vida y la salud del paciente, cuando establece las siguientes pautas a observar:

- Debe respetarse la voluntad del Testigo de Jehová cuando la misma ha sido informada y expresa en relación con los tratamientos ofertados. Ninguna autoridad está facultada para imponer uno diferente.

- Las entidades encargadas de prestar el servicio de salud pueden acudir a tratamientos que no impliquen transfusiones de sangre, si se encuentran disponibles según el caso. Este aspecto es un desarrollo del criterio de necesidad que se debe estudiar en las tensiones entre postulados constitucionales.

- De esta manera, se busca respetar la voluntad del paciente, pero sin desconocer las obligaciones de protección de sus derechos a la vida y salud.

\section{CONCLUSIONES}

El análisis efectuado anteriormente nos lleva a concluir que, contrario a lo que prima facie podría entenderse del análisis desprevenido de la jurisprudencia de la Corte Constitucional colombiana relacionada con las transfusiones de sangre a miembros de la comunidad de los Testigos de Jehová, esta no le da prelación absoluta a la libertad religiosa del paciente, sino que busca realizar, en la mayor medida posible, el deber estatal de proteger la vida de sus asociados, a partir de la introducción de algunos criterios a observar por parte de quienes intervienen en este tipo de casos. Muestra de ello la encontramos en la relevancia que cobra el consenti- 
miento informado al paciente, así como la oferta de otros procedimientos en los que no sea requerida la transfusión de sangre.

No estamos entonces ante un evento de jerarquización de derechos, en donde la libertad religiosa se impone al derecho a la salud o sobre el deber estatal de asegurar la vida de sus asociados, sino de un caso en el que se busca ofrecer a la persona una gama de opciones que se avengan a la necesidad de recuperar la salud, pero frente a las cuales el paciente podrá ejercer su autonomía y, escoger o no, aquella que compagine con sus creencias religiosas.

Puntualmente, el análisis efectuado nos permite concluir lo siguiente:

- La jurisprudencia constitucional colombiana presenta una noción de salud de contenido amplio que abarca la esfera física, mental y social del paciente, pero que se encuentra igualmente ligada a las variantes presupuestales.

- En el caso de los Testigos de Jehová, la Corte Constitucional ha reconocido la necesidad de observar y proteger su libertad religiosa, excepto en aquellos casos de eventos extremos que involucran Testigos de Jehová menores de edad, pues allí debe concurrir la opinión de los padres para tomar una decisión.

- Resulta cuando menos curiosa la reiterada alusión a la limitación de la libertad religiosa, según la cual este derecho no puede ir en contravía del cuidado sobre la propia vida del paciente, ni de los derechos de terceros, o los derechos colectivos. ¿Qué ocurre si no existen alternativas de tratamiento para el paciente, y la única opción para salvaguardar su vida es una transfusión de sangre, rechazada por el Testigo de Jehová?, ¿Deberá haber una intromisión tal del Estado que le permita desconocer la voluntad del paciente? Este interrogante, a pesar de parecer remoto en virtud de los avances científicos, ameritaría una respuesta precisa de la Corte Constitucional.

\section{REFERENCIAS BIBLIOGRÁFICAS}

\section{Referencias jurisprudenciales:}

1. Corte Constitucional, Sala Plena, (29 de septiembre de 2010) Sentencia C-776 [Magistrado Ponente Dr. Jorge Iván Palacio Palacio]

2. Corte Constitucional, Sala de Revisión, (noviembre de 1996) Sentencia T-474 del 25 [Magistrado Ponente Dr. Fabio Morón Díaz]

3. Corte Constitucional, Sala Novena de Revisión, (15 de agosto de 2002) Sentencia T-659 [Magistrada Ponente Dra. Clara Inés Vargas Hernández]

4. Corte Constitucional, Sala Quinta de Revisión, (4 de octubre de 2002) Sentencia T-823 [Magistrado Ponente Dr. Rodrigo Escobar Gil] 
5. Corte Constitucional, Sala Novena de Revisión, (10 de mayo de 2005) Sentencia T-471 [Magistrada Ponente Dra. Clara Inés Vargas Hernández]

6. Corte Constitucional, Sala Segunda de Revisión, (2 de febrero de 2010) Sentencia T-052 [Magistrado Ponente Dr. Mauricio González Cuervo]

7. Corte Constitucional, Sala Segunda de Revisión, $\left(1^{\circ}\right.$ de febrero de 2016) Sentencia T-476 [Magistrado Ponente Dr. Luis Guillermo Guerrero Pérez]

8. Corte Constitucional, Sala Séptima de Revisión, (7 de mayo de 2018) Sentencia T-171 [Magistrada ponente Dra. Cristina Pardo Schlesinger]

9. Corte Constitucional, Sala Quinta de Revisión, (4 de octubre de 2002) Sentencia T-823 [Magistrado ponente Dr. Rodrigo Escobar Gil]

10. Corte Constitucional, Sala Plena, ( $1^{\circ}$ de octubre de 2015$)$ Sentencia SU-626 [Magistrado ponente Dr. Mauricio González Cuervo]

\section{Referencias doctrinales:}

11. Alexy, R. (2016). La doble naturaleza del Derecho. [Trad.] Madrid: Editorial Trotta.

12. Alexy, R. (2012). Teoría de los derechos fundamentales. [Trad.] Madrid: Centro de Estudios Políticos y Constitucionales.

13. Arango, R. (2012). El concepto de derechos sociales fundamentales. Bogotá: Editorial Legis.

14. Arenas, G. (2018). El derecho colombiano de la seguridad social. Bogotá: Editorial Legis.

15. Araújo, J. (2015). Filosofía o teoría del derecho constitucional. Bogotá: Grupo Editorial Ibáñez.

16. Bernal, C. (2008). El derecho de los derechos. Bogotá: Universidad Externado de Colombia.

17. Bernal, C. (2018). Derechos, cambio constitucional y teoría jurídica. Bogotá: Universidad Externado de Colombia.

18. Bidart, G. (2016). Compendio de derecho constitucional. Buenos Aires: Ediar.

19. Bidart, G. (1988). Los equilibrios de la libertad. Buenos Aires: Ediar.

20. Clérico, L. (2009). El examen de proporcionalidad en el derecho constitucional. Buenos Aires: Editorial Eudeba.

21. Besio R, Mauricio, \& Besio H, Francisca. (2006). Testigos de Jehová y transfusión sanguínea: reflexión desde una ética natural, en Revista chilena de obstetricia y ginecología, 71(4), 274-279, disponible en https://dx.doi.org/10.4067/S0717-75262006000400010 
22. Delgado, C. (2018). Políticas públicas, juez constitucional y derechos sociales. Bogotá: Grupo Editorial Ibáñez.

23. Cepeda, M. (2007). Polémicas constitucionales. Bogotá: Editorial Legis.

24. Ferreyra, R. (2015). Fundamentos constitucionales. Buenos Aires: Editorial Ediar.

25. Haberle, P. (2007). El Estado constitucional. Buenos Aires: Editorial Astrea.

26. Pregno, E. (2013). “Transfusiones de sangre y Testigos de Jehová: comentario al fallo de la Corte Suprema de Justicia de la Nación Argentina. Albarracín Nieves, Jorge Washington s/ Medidas precautorias, del 01/06/2012", en Revista de Derecho Público año 22, Número 43, agosto de 2013, Buenos Aires, Argentina. 